Editorial

\title{
Towards a renewed public health regulatory and surveillance role in water, sanitation and hygiene
}

\author{
Hamed Bakir ${ }^{1}$, Mahdi Hadi ${ }^{2}$ and Mey Jurdi ${ }^{3}$
}

Evidence from the burden of disease studies indicates that improving water, sanitation and hygiene (WSH) is a primary disease prevention measure $(1,2)$. It prevents $57 \%$ of diarrheal deaths, contributes to prevention and management of neglected tropical diseases, and is the first line of defence against cholera (1-3). Moreover, water and sanitation (W\&S) services and hygiene contribute to programme initiatives including new-born, child and maternal health; infection prevention and control; universal health care; antimicrobial resistance; and health emergencies (4). Access to $\mathrm{W} \& \mathrm{~S}$ services is recognized by the United Nations as a human right.

However, despite improvements in W\&S between 1990 and 2015, inadequate WSH conditions account for 845810 deaths and 56.6 million disability-adjusted life years (DALYs) from diarrheal diseases every year (2). In the Eastern Mediterranean Region (EMR), inadequate WSH conditions account for 79939 annual deaths and 6.1 million DALYs from diarrhoeal diseases $(1,2)$, of which 70845 occur in Afghanistan, Pakistan, Somalia, Sudan and Yemen, where WSH conditions are highly deficient $(1,2,5)$. As the EMR countries approach the Sustainable Development Goals (SDGs), countries still have to deal with the unfinished business of ending open defecation and provision of adequate $\mathrm{W} \& \mathrm{~S}$ services. Recent reports indicate that 51.7 million people in the Region still practice open defecation, 84.4 million (13\%) remain without even basic water services, and 175 million (27\%) remain without basic sanitation services (5).

The strong focus of SDG 6 on safely managed W\&S services presents additional challenges to countries to elevate W\&S services from basic to safely managed (5). Ninety per cent of the population in 9 countries (Bahrain, Jordan, Kuwait, Lebanon, Morocco, Oman, Pakistan and Tunisia) have access to basic water service but only $57.2 \%$ of the services are safely managed (5). Pakistan reports $89 \%$ access to basic water services but only $36 \%$ of the services are safely managed. Meanwhile, $89 \%$ of the population in 14 countries (Bahrain, Egypt, Iraq, Jordan, Kuwait, Lebanon, Libya, Morocco, Qatar, Saudi Arabia, Somalia, Tunisia, UAE and West Bank and Gaza) have access to basic sanitation services but only $56 \%$ of the services are safely managed (5). In Lebanon, access to basic services is $95 \%$ but only $20 \%$ of these services are safely managed. Finally, in Egypt access to basic service access is $93 \%$ but only $60 \%$ of the services are safely managed (5).

Water, sanitation and hygiene services in the EMR countries are developed and managed under increasingly difficult security and physical environments. Conflicts and political unrest have reversed two decades of improvement in WSH conditions in Libya, the Syrian Arab Republic, and Yemen, and hinders extension of services in Afghanistan and Somalia. In addition, natural water scarcity is aggravated by population growth, urbanization and climate change. Moreover, the high cost of developing water sources defers the extension of water services to the unserved. Interrupted and intermittent drinking water supplies are common practice leading to compromised water safety and insufficient domestic water supplies for sustaining hygiene. Regulated and unregulated irrigation with wastewaters is common and the nsafe management of sanitation systems pollutes the environment. .

To counter these issues effectively, national health-based regulations of W\&S services must be developed and enacted for health protection, including: household drinking water security (i.e., sustained availability of sufficient quantities of safe water on the premises when needed); safe management of water systems; safe management of sanitation systems; safe use of wastewater in irrigation with consideration for workers' protection and food safety; W\&S and hygiene services in health care facilities and education institutions; and W\&S services in emergencies.

However, providing W\&S services is a complex undertaking that involves three interdependent functions spread across multiple governmental ministries and agencies (6-11). First, governance and regulatory frameworks that set the service targets and service standards, policies, resource allocation, and institutional responsibilities. Here, the public health institutions remain the primary contributor of health-based evidence for the service targets, standards and other regulatory tools (6-11). Second, WSH services provision and 
management through safely managed systems by specialized water and sanitation agencies. Third, independent oversight surveillance, which is typically a public health function to verify safety of services in order to provide feedback to the service providers and to the regulatory processes $(6,11)$. Additionally, surveillance reports on the public health impacts of WSH services are required to generate health evidence for the regulatory process.

The Islamic Republic of Iran, Jordan and Tunisia enjoy high water services coverage. Evidence from these Member States indicates that sustained and strong engagement of public health institutions in regulating and monitoring water services have made it possible to report on the safe management of water services, and to narrow the gap between basic and safely managed services (5). Unfortunately, the last two decades have seen public health institutions in most other EMR countries distancing themselves from their regulatory and surveillance role of W\&S services.

Any transition to an era of safely managed W\&S services under SDGs direction implies the necessity of additional resources allocation to uplift and sustain W\&S services. The SDGs emphasize the shift to country-driven target setting, financing, implementing and monitoring. This shift requires harnessing institutional capacities and processes of national stakeholders for governing, regulating, managing and monitoring WSH services according to internationally accepted World Health
Organization (WHO) norms and guidelines (6-12).

Thus, it is critical that public health ministries strengthen their regulatory and surveillance roles. Moreover, they must engage in communicating health evidence and advocating with key WSH sector players. Such WSH stakeholders set priorities and thereby influence the allocation of resources to priority prohealth WSH policies and programmes. To this end, the WHO regional WSH programme needs to continue to provide authoritative technical guidance to health ministries and other WSH stakeholders on the application of WHO's normative guidelines to regulate, manage and monitor WSH services including under emergencies.

\section{References}

1. World Health Organization. Preventing disease through healthy environments: A global assessment of the burden of disease from environmental risks. Geneva: World Health Organization; 2016 (http://apps.who.int/iris/bitstre am/10665/204585/1/9789241565196_eng.pdf, accessed 3 October 2017)

2. World Health Organization. Preventing diarrhea through better water, sanitation and hygiene: exposures and impacts in low-and middle-income countries. Geneva: World Health Organization, 2014 (http://apps.who.int/iris/bitstr eam/10665/150112/1/9789241564823_eng.pdf, accessed 3 October 2017)

3. World Health Organization. Water sanitation and hygiene for accelerating and sustaining progress on neglected tropical diseases-A global strategy 2015-2020. Geneva: World Health Organization; 2015 (http://www.who.int/water_sanitation health/events/wash-ntd-infographic.pdf accessed 3 October 2017).

4. World Health Organization. Global Action Plan on Antimicrobial Resistance. Geneva: World Health Organization; 2015 (http://www.wpro.who.int/entity/drug_resistance/resources/global_action_plan_eng.pdf, accessed 3 October 2017).

5. World Health Organization and the United Nations Children's Fund. Progress on drinking water, sanitation and hygiene: 2017 update and SDG baselines. Geneva: World Health Organization; 2017 (http://www.who.int/mediacentre/news/ releases/2017/launch-version-report-jmp-water-sanitationhygiene.pdf?ua=1, accessed 3 October 2017)

6. World Health Organization. Guidelines for drinkingwater quality $-4^{\text {th }}$ edition. Geneva: World Health Organization; 2011 (http://apps.who.int/iris/bitstre am/10665/44584/1/9789241548151_eng.pdf, accessed 3 October 2017)
7. World Health Organization. Water safety plan manual (WSP manual) step-by-step risk management for drinking-water suppliers. Geneva: World Health Organization; 2009 (http:// apps.who.int/iris/bitstream/10665/75141/1/9789241562638_ eng.pdf, accessed 3 October 2017).

8. World Health Organization. Water safety in buildings. Geneva: World Health Organization; 2011 (http://apps.who.int/iris/ bitstream/10665/76145/1/9789241548106_eng.pdf, accessed 3 October 2017).

9. World Health Organization. Guidelines for safe recreational water environments. Volume 1: Coastal and fresh waters. Geneva: World Health Organization; 2003 (http://apps.who. int/iris/bitstream/10665/42591/1/9241545801.pdf, accessed 3 October 2017).

10. World Health Organization. Guidelines for safe recreational water environments. Volume 2: Swimming pools and similar environments. Geneva: World Health Organization; 2006 (http:// apps.who.int/iris/bitstream/10665/43336/1/9241546808_ eng.pdf, accessed 3 October 2017).

11. World Health Organization. Guidelines for the safe use of wastewater, excreta and greywater. Geneva: World Health Organization; 2006 (http://apps.who.int/iris/bitstream/10665/78265/1/9241546824_eng.pdf, accessed 3 October 2017).

12. World Health Organization. Sanitation safety planning - Manual for safe use and disposal of wastewater, greywater and excreta. Geneva: World Health Organization; 2015 (http://apps. who.int/iris/bitstream/10665/171753/1/9789241549240_eng. pdf, accessed 3 October 2017). 